\title{
La delimitación de la función preventiva de la responsabilidad civil en el Código Civil y Comercial Argentino*
}

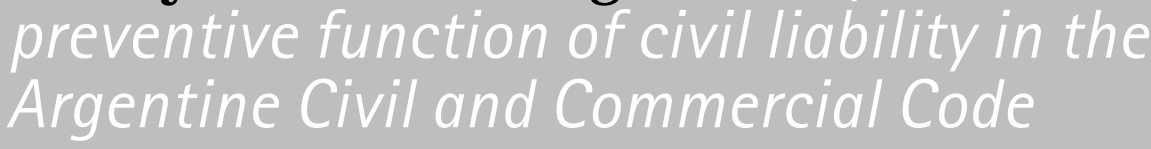

\section{Claudio Fabricio Leiva**}

\section{RESUMEN}

En el presente trabajo, trataremos los fundamentos y los alcances de la función preventiva de la responsabilidad civil, teniendo en cuenta las discusiones doctrinarias que el tema ha generado. Concentraremos nuestro análisis en la delimitación de su consagración normativa en el Código Civil y Comercial de la Nación que rige en Argentina, desde el primero de agosto de 2015. Este cuerpo normativo dispone en el artículo 1708 la dualidad de funciones que se le asigna a la responsabilidad civil preventiva y resarcitoria, excluyéndose la función sancionatoria de esta regulación.

Destacamos que se contempla en forma expresa el deber genérico de prevención, siendo necesario determinar los límites de su exigibilidad, es decir, a quién alcanza este deber. Para su concreción, el legislador ha determinado algunos lineamientos para el desarrollo de la prevención de los daños. Ello se refleja, asimismo, en el contenido de la sentencia judicial que admite una acción preventiva de daños. El juez debe ponderar los criterios de menor restricción posible y de medio idóneo para asegurar la eficacia en la obtención de la finalidad.

PALABRAS CLAVE: Responsabilidad civil, daños, deber general de prevención, acción preventiva, requisitos de la acción preventiva, legitimación, sentencia.

\begin{abstract}
The present paper deals with the bases and scope of the preventive function of civil liability, taking into account the doctrinal discussions that the subject has generated. We focus our analysis on its enshrinement in the Civil and Commercial Code that has been in force in the Argentine Nation since 1st August 2015. In Article 1708, this regulatory framework stipulates the duality of functions assigned to preventive and reparatory civil liability, excluding the sanctioning/penalizing function of this framework. In this regard, we highlight that this expressly considers the generic duty of prevention. It is necessary to set out the limits of its enforceability, namely to identify those who fall within the scope of this duty. In order to implement this framework, the legislature has established guidelines for the prevention of damage, which is reflected, moreover, in the content of the court ruling that recognizes an action preventing damages, wherein the judge must consider the least restrictive criteria possible and the most ideal measure to effectively achieve the objective.
\end{abstract}

KEY WORDS: Civil liability, damages, prevention, general duty of prevention, preventive action, requirements for preventive action, legitimation/ legitimization/legalization, sentence/ruling/verdict.

\footnotetext{
* Artículo de investigación. Recibido el 15 de octubre de 2018 y aceptado para su publicación el 7 de agosto de 2019.

** Profesor titular en la Facultd de Ciencias Económicas y Juridicas de la Universidad del Aconcagua, Argentina. (cleiva@jus.mendoza.gov.ar) orcid.org/0000-0002-0582-4434
} 


\section{SUMARIO}

1. La responsabilidad civil y sus funciones: visión actual de la prevención de daños

2. Tipologias de prevención del daño

3. Consagración normativa de la función preventiva de la responsabilidad civil en el marco del Código Civil y Comercial Argentino

4. La acción preventiva: requisitos y alcance

5. La legitimación sustancial activa y pasiva en la acción preventiva

6. La sentencia preventiva de daños

7. Reflexiones de cierre

\section{La responsabilidad civil y sus funciones: visión actual de la prevención de daños}

En el presente trabajo pretendemos delimitar el alcance de la función preventiva de la responsabilidad civil, tal como ha sido regulada en el Código Civil y Comercial Argentino, vigente a partir del primero de agosto del 2015.

Justamente, el artículo 1708 del Código inicia con el título "Responsabilidad civil" como una de las fuentes de las obligaciones. Este determina qué funciones debe desarrollar la responsabilidad, en estos términos: "Las disposiciones de este título son aplicables a la prevención del daño y a su reparación”. ${ }^{1}$

El Código establece que la responsabilidad civil no debe limitarse exclusivamente al resarcimiento de los daños ya acaecidos, sino que avanza en la propuesta, regulando, en forma prioritaria, la función preventiva. ${ }^{2}$ Con estas ideas introductorias en torno a la prevención del daño, parece importante destacar que el artículo 51 del Código Civil y Comercial de la Nación dispone: "Inviolabilidad de la persona humana. La persona humana es inviolable y en cualquier circunstancia tiene derecho al reconocimiento y respeto de su dignidad”. Por su parte, el artículo 52 regula las afectaciones de la dignidad

\footnotetext{
'Véase: Lorenzett, Ricardo, "Aspectos valorativos y principios preliminares del Anteproyecto de Código Civil y Comercial de la Nación", La Ley, 23 de abril, 2012; AlterinI, Atilıo AnibAL, "Soluciones del Proyecto de Código en materia de responsabilidad civil", La Ley, 30 de julio, 2012; Galdós, Jorge Marıo, "La responsabilidad civil (parte general) en el Anteproyecto", La Ley, 11 de junio, 2012.

2 Lorenzetti, Ricardo Luis, Normas fundamentales del derecho privado, Santa Fe, Rubinzal-Culzoni, 1995, p. 280. "El derecho privado tradicional se basaba en que la tutela preventiva es tarea del Estado y del derecho administrativo; su función era entonces la tutela represiva, resarcitoria; se actuaba después de la lesión. Actualmente, con el fenómeno de la difusión del poder, que supone la titularización individual y difusa como modo de actuación social, surge el nuevo paradigma de análisis de estas nuevas herramientas [...] En el derecho civil, surge la tutela inhibitoria que permite prevenir el daño antes de que éste se produzca e incursionar en el orden social mediante el señalamiento de conductas obligatorias."
} 
de la personas. "La persona humana afectada en su intimidad personal o familiar, honra o reputación, imagen o identidad, o que de cualquier modo resulte menoscabada en su dignidad personal, puede reclamar la prevención y reparación de los daños sufridos, conforme a lo dispuesto en el libro tercero, título 5 , capítulo $1 .{ }^{3}$

La persona y sus derechos fundamentales, hoy, constituyen el epicentro del sistema. Muchas veces, cuando se trata de daños provocados a esta categoría de derechos, la indemnización puede resultar insuficiente. Así, se torna prioritario desplegar mecanismos para evitar los daños, más que implementar su reparación cuando estos ya se han producido. ${ }^{4}$

Según explica Prevot, la idea de añadir una finalidad preventiva a la indiscutible función reparadora de la responsabilidad civil ha sido puesta de relieve por los autores que se han ocupado del análisis económico del derecho; esto con el fin de evitar o reducir los comportamientos dañosos. Así, se sostiene que a) No se trata de sacrificar las exigencias compensatorias en aras de la prevención; b) El análisis de los aspectos funcionales de la responsabilidad civil debe realizarse con sustento en las normas positivas y principios jurídicos vigentes al momento de llevarse a cabo la interpretación. El objeto de la prevención o disuasión de conductas dañosas puede ser perfectamente deducido del sistema de responsabilidad civil tal como fue diseñado por el codificador de fines del siglo XIX, es decir, en clave subjetiva; c) La prevención del daño no es una tarea que resulta extraña al derecho en general ni al derecho civil en particular. ${ }^{5}$

Ahora bien, el deber genérico de no dañar reviste rango constitucional (artículo 19 de la Constitución nacional). Cada sujeto puede conducirse en la vida social del modo en que libremente elija, con el límite de no perjudicar los derechos de terceros, ni ofender el orden ni la moral pública. ${ }^{6}$

Desde la doctrina, este principio debe ser interpretado, primero, en forma literal; no tanto en el sentido de indemnizar el daño ya causado (intervención ex post), sino de evitación del daño (actuación ex ante). Consecuentemente, cabe postular que hay una exigencia ética y jurídica de "no dañar", la cual

\footnotetext{
${ }_{3}^{3}$ Por lo demás, el artículo primero del Código Civil y Comercial de la Nación se ocupa de las fuentes y su aplicación: "Fuentes y aplicación. Los casos que este Código rige deben ser resueltos según las leyes que resulten aplicables. La interpretación debe ser conforme con la Constitución Nacional y los tratados en los que la República Argentina sea parte. A tal fin, se tendrá en cuenta la jurisprudencia en consonancia con las circunstancias del caso. Los usos, prácticas y costumbres son vinculantes cuando las leyes o los interesados se refieren a ellos o en situaciones no regladas legalmente, siempre que no sean contrarios a derecho."

${ }^{4}$ Cossari, Maximiliano, Prevención y punición en la responsabilidad civil, Buenos Aires, El Derecho, 2017, pp. 58 y ss.

${ }^{5}$ Prevot, Juan Manuel, "La prevención del daño en la codificación del siglo xix y en el Código Civil Argentino", Revista de Derecho de Daños, núm. 2, pp. 177 y ss. -en especial la página 183-.

${ }^{6}$ Kemelmajer de Carluccl, Aida, "La Ley sobre Riesgos del Trabajo 24.557 y los principios generales del Derecho de Daños desde la óptica del Derecho Constitucional", Revista de Derecho Privado y Comunitario, p. 270.
} 
requiere, ante todo, impedir daños injustos, al margen de reparar los causados. Existe un deber de no perjudicar, salvo causa de justificación. ${ }^{7}$

El principio alterum non laedere ordena precisamente no dañar al otro, y puede interpretarse como actuar antes de que se concrete el daño. Siempre es mejor que un daño no ocurra a que un daño se indemnice luego de ocurrido. La reparación plena es solo un principio que no siempre cubre todos los daños, todos los damnificados y todas las consecuencias. ${ }^{8}$

Perdía advierte que prevenir una ruptura en el orden general es tender a un bien mayor. El bienestar social se quiebra cuando se producen supuestos de daños en los no se puede restablecer el orden por medio de la reparación, o cuando se afecta a un grupo tan grande que la indemnización en modo alguno logrará saciar el interés individual de todos y cada uno de ellos (suponiendo que tengan acceso a las vías pertinentes para exigirla). La prevención es la herramienta que tiene la responsabilidad civil para atender al interés del grupo afectado por las situaciones dañosas. Estos, a su vez, por medio de una vía anticipada, podrán ejercer la tutela de sus intereses vitales. Así, se ahorra una herida incurable en la conciencia colectiva que agrupa cada una de sus individualidades. ${ }^{9}$

El principio de constitucionalización del derecho de la responsabilidad civil radica en buscar el deber de no dañar en la propia Carta Magna y en el conjunto de tratados internacionales que ostentan jerarquía constitucional. En otros términos, el derecho a no ser dañado y, en su caso, a ser indemnizado, encuentra su fuente en la propia Constitución nacional.

En tal sentido, los principios constitucionales modifican las jerarquías de las situaciones jurídicas privadas y crean una nueva fuente, superior y ordenadora. De tal modo, la propia Carta Magna funge como la causa fuente directa del principio deber de no dañar (artículo 19). Por ello, resulta claro que este presupone de manera previa y autónoma al deber de reparar el perjuicio ocasionado, el de su evitación. Solo se puede concluir que la función preventiva de la responsabilidad civil que ahora reconoce el nuevo código tiene linaje constitucional. ${ }^{10}$

\footnotetext{
7 Zavala de González, Matilde, "Función preventiva de daños", La Ley, 3 de octubre, 2011. En las XXIII Jornadas Nacionales de Derecho Civil, celebradas en Tucumán en setiembre de 2011, se sostuvo que "el principio de prevención constituye un principio general del Derecho de Daños".

${ }^{8}$ López Herrera, Edgardo, "La función preventiva de la responsabilidad civil y su relación con las otras funciones", Revista de Derecho de Daños, 2008-2, p. 201.

9 Perdia, Natal, "La responsabilidad preventiva en el nuevo Código Civil y Comercial", Revista de Responsabilidad Civil y Seguros, núm. 9, p. 26.

10 Sema, José Ignacio, "La función preventiva de la responsabilidad civil en el Código Civil y Comercial. Fundamentos de su reconocimiento legal", Pensamiento civil, p. 1. Disponible en: https://www.pensamientocivil.com.ar/ doctrina/2173-funcion-preventiva-responsabilidad-civil-codigo-civil-y-comercial
} 


\section{Tipologías de prevención del daño}

La idea de prevención ha estado presente en el enfoque tradicional de la responsabilidad civil, desde el cual la reparación era prioritaria. La doctrina avizoraba que la indemnización de los daños y perjuicios derivados de un hecho dañoso cumplía una doble función: reparadora y preventiva. En este orden de ideas, la indemnización de daños cumple una función resarcitoria o reparadora en cuanto la víctima obtiene un paliativo para el daño que ha sufrido, ya sea en especie o en dinero, con el fin de volver al estado anterior de las cosas. Sin embargo, esa misma indemnización desempeñaba una función preventiva en cuanto a que los sujetos, presionados psicológicamente por esa consecuencia jurídica, se comportarían conforme las condiciones de cuidado para no causar daños a terceros. ${ }^{11}$

Messina de Estrella Gutiérrez señala que el rol normativo de la responsabilidad se manifiesta, en principio, como una incitación a evitar comportamientos socialmente reprobables. La autora expresa que muchos autores reconocen en la responsabilidad civil un medio de disuasión de comportamientos antisociales nocivos, y le asignan a ese papel un sentido general.

Es cuestionable si esa función tiene eficacia real en el plano individual, es decir, en relación con el sujeto que causó el daño, porque la mayoría de los accidentes se producen por el uso de cosas peligrosas. Entonces, los efectos son casi siempre imputables al azar, a la imperfección técnica de los objetos o a las dificultades del hombre para conocer sus mecanismos.

En cambio, las condenas civiles - aunque sean individuales- pronunciadas en sentencias sobre responsabilidad profesional conservan un efecto disuasivo real, a pesar de que sean garantizadas por un seguro. La acción de responsabilidad civil aparece como el medio para la afırmación de ciertos derechos, un medio de compeler, de perfeccionar y de renovar el sistema jurídico existente. Dentro de esa función, es evidente que la responsabilidad civil no puede ser suplida por los procesos de socialización directa de riesgos, los cuales de ninguna manera pueden jugar aquel rol. ${ }^{12}$

Vergara indica que el hecho de que la responsabilidad civil ordene bajo determinados requisitos la reparación del daño implica la puesta en marcha de un orden coactivo. Ante tal situación, un sujeto es condenado (sancionado) a pagar o a hacer algo y, como para este sujeto dicha condena implica una situación

\footnotetext{
11 Zavala de González, Matilde, Resarcimiento de daños, presupuestos y funciones del derecho de daños, tomo 4, Buenos Aires, Hammurabi, 1999, pp. 424.

12 Messina de Estrella Gutiérrez, Graciela N., La responsabilidad civil en la era tecnológica. Tendencias y prospectiva, Buenos Aires, Abeledo Perrot, 1997, p. 213 y ss.
} 
desventajosa, todo indica que querrá racionalmente evitarla; por ello, intentará prevenir de transitar algo que no le conviene. De tal manera, existe una relación entre la sanción y la prevención. La idea es clara en la medida que se sancionen ciertas violaciones, dichas sanciones pueden funcionar como incentivos para tomar precauciones. ${ }^{13}$

Por su parte, Acciarri señala que esta noción de prevención general se refiere a los casos donde la prevención surge de la decisión del propio autor de la conducta potencialmente riesgosa. El efecto disuasivo de las normas tradicionales de responsabilidad civil constituye una instancia clara de este tipo de prevención. Ante la posibilidad de enfrentarse al pago de una indemnización, cada persona puede decidir si prefiere colocarse en esa situación o adoptar las medidas de prevención que, a la vez, reducirán la probabilidad de causar ese daño (o su magnitud, en caso de acontecer), así como la probabilidad correlativa de ser condenada al pago de la indemnización correspondiente (o su magnitud).

En este orden de ideas, es posible afirmar que el sistema de responsabilidad civil genera incentivos para prevenir, cuando determina un deber de resarcir. Desde este punto de vista, la función relación resarcitoria será instrumental a la función relación preventiva. ${ }^{14}$

En los Principios de derecho europeo de la responsabilidad civil, capitulo 10. "Indemnización", artículo 10:101 regula la naturaleza y objeto de la indemnización: "La indemnización es un pago en dinero para compensar a la víctima, es decir, para reestablecerla, en la medida en que el dinero pueda hacerlo, en la posición que hubiera tenido si el ilícito por el que reclama no se hubiera producido. La indemnización también contribuye a la finalidad de prevenir el daño”.

Desde esta perspectiva, la fijación de una indemnización de daños y perjuicios cumple una función reparadora y, al propio tiempo, disuasoria de conductas semejantes, tal como lo planteaban las teorías de la justificación de las penas, provenientes del derecho penal. En este sentido, se puede hablar de una función preventiva indirecta, cuestión que se ha visto revitalizada con la 248 propuesta de la teoría de los daños punitivos, además de la función sancionadora implícita en esta noción.

El polémico tema de los daños punitivos comienza con la denominación misma. En ciertos supuestos, esta propone la aplicación de penas privadas por encima de los valores que se fijen en carácter de indemnización de daños y perjuicios, destinándolas ya sea al propio damnificado, al Estado o a organismos

\footnotetext{
${ }^{13}$ Vergara, Leandro, "La prevención en el derecho de la responsabilidad civil", Revista de Responsabilidad Civil y Seguros, vol. 5, núm. 6, p. 14.

${ }^{14}$ Acciarri, Hugo A., "Funciones del derecho de daños y de prevención", La Ley, 2013-A, p. 717.
} 
de bien público. Justamente, esta pena privada está íntimamente asociada a la prevención indirecta, en cuanto se busca la evitación o prevención de ciertas inconductas futuras, que pueden ocasionar daños, por ejemplo, en caso de daño ambiental o a los consumidores. ${ }^{15}$

Sin embargo, la prevención del daño comprende otro aspecto que supera la finalidad preventiva, desde el punto de vista psicológico ya descrito. Aparece otro aspecto que suele denominarse "función preventiva directa", el cual consiste en desplegar conductas positivas en aras de la concreta evitación de la producción de un perjuicio en particular, o de su agravamiento, si ya se ha producido.

No está de más acotar que la escuela del análisis económico del derecho asigna a la responsabilidad civil las siguientes funciones: 1. La reducción de los costos primarios que pudieran ocurrir. Para esto se obliga al potencial causante de los daños que asuma los costos económicos, liberando a la víctima de asumirlos. Así, el potencial causante recibe incentivos para tomar precauciones y, así, evitar asumir el costo de los daños; 2. El otorgamiento de la debida compensación a las víctimas mediante la reducción de los costos secundarios derivados de los daños ya ocurridos. Estos costos se minimizan mediante el traslado del peso económico a quienes disfrutan de una mejor situación patrimonial para soportarlo, y la distribución social del costo de los daños por un sistema de precios o de seguros; 3 . La reducción de los costos terciarios, los cuales son derivados de los errores e ineficiencias del sistema de responsabilidad civil. ${ }^{16}$

La prevención específica difiere de la general, en cuanto al sujeto que puede tomar la decisión de prevenir. Así, en la prevención general, será el autor potencial de la actividad susceptible de causar un daño; en la específica, será un funcionario estatal. De tal modo, será el juez o un funcionario administrativo quien decidirá la posibilidad de realización o la continuidad de una actividad potencialmente dañosa. La tutela inhibitoria es un vehículo típico de este efecto preventivo, de actuación judicial. Clausuras administrativas, secuestro de vehículos y órdenes de demolición de construcciones son fuentes representativas de ese mismo efecto preventivo, pero generado por vías administrativas. ${ }^{17}$

\footnotetext{
${ }^{15}$ Véase Zavala de González, Matilde, Resarcimiento de daños, presupuestos y funciones del derecho de daños, tomo 4, Buenos Aires, Hammurabi, 1999, pp. 571 y ss; Pizarro, Ramón y Vallespinos, Carlos, Instituciones de derecho privado. Obligaciones, tomo 3, Buenos Aires, Hammurabi, 2000, pp. 245 y ss. Cossari, Maximiliano, Prevención y punición en la responsabilidad civil, Buenos Aires, El Derecho, 2017.

${ }^{16}$ Morales Hervias, Rómulo, "Responsabilidad civil y análisis económico del derecho", Revista de Responsabilidad Civil y Seguros, vol. 3, núm. 4, pp. 24-25.

${ }^{17}$ Acciarri, Hugo A., "Funciones del derecho de daños y de prevención", La Ley, 2013-A, p. 717.
} 


\section{Consagración normativa de la función preventiva de la responsabilidad civil en el marco del Código Civil y Comercial Argentino}

La función preventiva de la responsabilidad caracteriza a uno de los actuales perfiles de esta rama de la ciencia jurídica, que, en este sentido, ha sido redefinida como el conjunto de actividades, instrumentos y métodos de actuación tendientes a evitar o disminuir los daños que, por razón de cualquier clase de accidentes, puedan sufrir las personas y los bienes. ${ }^{18}$

El artículo 1710 del Código impone el deber de prevención de los daños, señala:

Toda persona tiene el deber, en cuanto de ella dependa, de: $a$ ) evitar causar un daño no justificado; b) adoptar, de buena fe y conforme a las circunstancias, las medidas razonables para evitar que se produzca un daño, o disminuir su magnitud; si tales medidas evitan o disminuyen la magnitud de un daño del cual un tercero sería responsable, tiene derecho a que éste le reembolse el valor de los gastos en que incurrió, conforme a las reglas del enriquecimiento sin causa; c) no agravar el daño, si ya se produjo". ${ }^{19}$

En forma genérica, este artículo coloca sobre toda persona el deber de adoptar conductas tendientes a la evitación de los perjuicios, "siempre que esa conducta dependa de ella”. Este condicionamiento de la norma impone analizar las circunstancias de cada caso particular para inducir la existencia de dicho deber de prevención. En tal sentido, el intérprete no ha de exigir el despliegue de conductas heroicas, sino en la medida en que la conducta preventiva del perjuicio haya dependido del sujeto. Como se destaca en los Fundamentos del Anteproyecto,

\footnotetext{
${ }^{18}$ Fernández Madero, Jaime, Derecho de daños. Nuevos aspectos doctrinarios y jurisprudenciales, Buenos Aires, La Ley, 2002, p. 721. El uso común de las palabras también resulta aplicable a la ciencia jurídica. Todos conocemos que es preferible prevenir que curar, pero el significado de la palabra prevención en cualquier diccionario nos indica la siguiente idea: "Acción e efecto de prevenir. Conjunto de disposiciones tomadas para evitar un riesgo". "Prevención", Diccionario Enciclopédico Marred, España, Trébol, 1998. Y si buscamos el verbo prevenir, encontramos lo siguiente: "Preparar, disponer con anticipación las cosas necesarias para lograr un objetivo. Conocer de antemano un perjuicio o daño. Evitar, estorbar o impedir. Informar, advertir, alertar. Afrontar una dificultad. Instruir las primeras diligencias para asegurar los resultados de un juicio. Prepararse por adelantado. Mostrarse a la defensiva". "Prevenir", Diccionario Enciclopédico Marred, España, Trébol, 1998.

${ }^{19}$ En las XXIII Jornadas Nacionales de Derecho Civil, celebradas en Tucumán en 2011, se sostuvo que "el deber de prevención del daño involucra la adopción de recaudos razonables para evitar su acaecimiento, la de hacer cesar el daño ya activado, y la de inhibir su agravamiento".
} 
"la posibilidad de prevenir debe encontrarse en su esfera de control, ya que, de lo contrario, se puede convertir en una carga excesiva que afecta la libertad".

Galdós advierte que el deber general de acción u omisión se centra en evitar o impedir el daño futuro, hacer cesar el daño actual, disminuir la magnitud y la extensión de las consecuencias del daño que comenzó a producirse. El autor entiende que la magnitud del daño se relaciona con el aspecto cualitativo (la entidad o medida del perjuicio) o su prolongación. Por ello, advierte que la tutela comprende todas las etapas y supuestos posibles de evitación de la "dañosidad". ${ }^{20}$

El inciso a) del artículo comienza por precisar que "toda persona tiene el deber de evitar causar un daño no justificado”. En otros términos, no existe tal deber si la producción de un daño encuentra como fundamento una causa de justificación, como sería, por ejemplo, la legítima defensa o el estado de necesidad o el ejercicio regular de un derecho, que el propio código regula en el artículo 1718.

En el Código, toda acción u omisión que causa un daño se considera antijurídica, si no concurre una causa de justificación que prive a la acción u omisión de antijuridicidad. El supuesto consagrado en el inciso a) del artículo 1710 parece ser la contracara del deber genérico de no dañar, que pesa indeterminadamente sobre todos los miembros de la comunidad, con sustento último en el artículo 19 de la Constitución nacional. Así como pesa sobre toda persona el deber de no dañar a los demás, pesa, de igual modo, el deber de evitar conductas perjudiciales.

El inciso b) impone el deber de adoptar medidas razonables tendientes a la evitación o disminución del agravamiento de un daño, conforme a la buena fe. Está claro que la buena fe configura un principio general del derecho, en tanto el Código, en su artículo 9, en el Título Preliminar, capítulo 3, establece que "los derechos deben ser ejercidos de buena fe". Así, supera la visión tradicional que le asignaba una función interpretativa en la etapa de la celebración, la ejecución y la interpretación de los contratos (artículo 1198 del Código Civil derogado). ${ }^{21}$

\footnotetext{
${ }^{20}$ Galdós, Jorge Mario, "La responsabilidad civil (parte general) en el Anteproyecto", La Ley, 11 de junio, 2012.

${ }^{21}$ De este modo, se consagra un deber de diligencia que pesa sobre toda persona. El artículo 1724 establece que "la culpa consiste en la omisión de la diligencia debida según la naturaleza de la obligación y las circunstancias de las personas, el tiempo y el lugar. Comprende la imprudencia, la negligencia y la impericia en el arte o profesión". Al respecto, debe apuntarse que el artículo 1725 del Código dispone que "cuanto mayor sea el deber de cobrar con prudencia y pleno conocimiento de las cosas, mayor es la diligencia exigible al agente y la valoración de la previsibilidad de las consecuencias".
} 
Cossari sostiene que el Código apela a un criterio de razonabilidad que deberá ser evaluado por los jueces en concreto, según las posibilidades reales de actuación. Es decir, no podrían exigirse conductas heroicas o extraordinarias, pero deben ser acordes con la magnitud del daño previsible, y eficaces para una prevención adecuada. El justo equilibrio requiere de una ponderación de los principios y los valores en juego, el ejercicio legítimo de los derechos y la mayor o menor certeza acerca de la previsibilidad del daño. ${ }^{22}$

Además, se precisa que, si las medidas de prevención logran evitar el daño producido por un tercero y del cual este sería responsable, quien adopte las medidas en cuestión podría reclamar de este tercero el reembolso de los gastos realizados en dicha actuación. Ello en consonancia con los principios del enriquecimiento sin causa, lo cual está regulado en los artículos 1794 y 1795 del Código. ${ }^{23}$

En el supuesto de que un sujeto que sea la potencial víctima adopte medidas preventivas, y estas eviten la producción o el agravamiento de daños, asumiendo la responsabilidad civil de quien debía tomar las medidas, el sujeto podrá recuperar los gastos por verse librado de una previsible responsabilidad civil. En consecuencia, por la actividad de un tercero, se obtienen los beneficios preventivos que busca el ordenamiento jurídico y se evita, adicionalmente, que el dañador vea afectado su patrimonio con la carga de una indemnización de daños o los costos judiciales a las que podría ser condenado. Es innegable que para el posible dañador aquella actuación implicaría un beneficio; no tendría que costear una indemnización cuantiosa, dado que otro habría tomado medidas para impedir perjuicios a terceros. ${ }^{24}$

Por último, el inciso c) impone no agravar el daño si este ya se produjo. Por ello, es dable extraer que se debe evitar la producción del daño, pero además se debe evitar su agravamiento.

A diferencia del deber general de no dañar, que pesa indeterminadamente sobre todos los miembros de una comunidad, el deber de evitación solo recae en aquellos casos en que es exigible el deber de previsibilidad de una acción propia. Asimismo, es exigible cuando está al alcance del sujeto o de las cosas que este emplea, pues tiene el deber de cuidarlas para evitar el daño. El

\footnotetext{
${ }^{22}$ Cossari, Maximiliano, Prevención y punición en la responsabilidad civil, Buenos Aires, El Derecho, 2017, p. 64.

${ }^{23} \mathrm{El}$ artículo 1794 del Código dispone: "Caracterización. Toda persona que sin una causa lícita se enriquezca a expensas de otro, está obligada, en la medida de su beneficio, a resarcir el detrimento patrimonial del empobrecido. Si el enriquecimiento consiste en la incorporación a su patrimonio de un bien determinado, debe restituirlo si subsiste en su poder al tiempo de la demanda". Mientras, el artículo 1795 dice: "Improcedencia de la acción. La acción no es procedente si el ordenamiento jurídico concede al damnificado otra acción para obtener la reparación del empobrecimiento sufrido".

${ }^{24}$ Cossari, Maximiliano, Prevención y punición en la responsabilidad civil, Buenos Aires, El Derecho, 2017, pp. 65-67.
} 
deber de impedir la consumación puede cumplirse mediante actos positivos (acciones) o negativos (omisiones), dependiendo de las concretas situaciones por las cuales atraviesa el sujeto actuante..$^{25}$

En todo el sistema normativo relativo al derecho de daños, subyace un deber de la propia víctima de "mitigar o atenuar el daño sufrido". Este deber exige al acreedor del resarcimiento la adopción de todas aquellas medidas que, atendidas las circunstancias del caso, se estimen razonables, para evitar o paliar la propagación de las consecuencias del daño causado. ${ }^{26}$

Zavala de González afırma que, así como no existe un derecho de perjudicar injustamente, el damnificado soporta la carga. Ello en función del propio interés de desplegar las diligencias ordinarias, para evitar la continuidad o el agravamiento del perjuicio. La víctima puede atenuar la obligación resarcitoria cuando es concausa del daño y cuando no elimina o no disminuye el daño imputable a otro, si estas omisiones sobrevinientes coadyuvan a desenvolver el perjuicio inicial. Es jurídicamente relevante la conducta del damnificado que, después del daño originario, guarda una injustificada pasividad sin intentar medidas razonables para paliarlo. ${ }^{27}$

Como sostiene Acciarri, la ley no es la instancia más adecuada para discernir quién debe prevenir y quién no, en cada una de las situaciones posibles. Probablemente, sobre la base de unas pocas directivas generales, son los jueces quienes están en mejor posición para construir un catálogo refinado de responsables, en cada género de casos que les toque sentenciar. La clave de la norma, en definitiva, no es esa aparente asignación tan general del deber de prevenir, sino sus acotaciones. Todos debemos prevenir, pero en cuanto dependa de nosotros, razonablemente, de buena fe y conforme a las circunstancias. ${ }^{28}$

\footnotetext{
${ }^{25}$ Padilla, RenÉ, Sistema de la responsabilidad civil, Buenos Aires, Abeledo Perrot, 1997, pp. 93-94.

${ }^{26} \mathrm{El}$ llamado duty of mitigation o duty of plaintiff to minimize damage constituye un criterio esencial para la determinación de la extensión cuantitativa del resarcimiento. En el derecho angloamericano, este criterio de delimitación cuantitativa de la indemnización se funda en el carácter compensatorio o resarcitorio y no punitivo de la indemnización, pero también en razones de política socioeconómica. Estas exigen la promoción del uso cuidadoso de los recursos para desincentivar con la exclusión del resarcimiento que el agraviado sufra pasivamente una pérdida que pudiera evitarse con un esfuerzo razonable.

${ }^{27}$ Zavala de González, Matilde, Resarcimiento de daños, presupuestos y funciones del derecho de daños, tomo 4 , Buenos Aires, Hammurabi, 1999, p. 292. Véase VeninI, Juan Carlos, "El deber de la víctima de mitigar el daño", Revista de Derecho de Daños, 2008-2, p. 81 y ss. Cabe decir que el Código Civil y Comercial dispone en el artículo 1729: "Hecho del damnificado. La responsabilidad puede ser excluida o limitada por la incidencia del hecho del damnificado en la producción del daño, excepto que la ley o el contrato dispongan que debe tratarse de su culpa, de su dolo, o de cualquier otra circunstancia especial".

${ }^{28}$ Acciarri, Hugo A., "El Genovese effect, los jueces y el Proyecto de Reforma al Código Civil argentino de 2012", Revista de Responsabilidad Civil y de Seguros, 2014-7, p. 5.
} 


\section{La acción preventiva: requisitos y alcance}

En materia de prevención, se observa la incorporación de pautas procesales en la regulación propuesta en el Código, debido a la necesidad de proporcionar eficacia a los institutos de derecho común. ${ }^{29}$ Tal es la consecuencia de la constitucionalización del derecho procesal civil y comercial, efecto que deriva necesariamente de la constitucionalización del derecho civil y comercial al que se encuentra vinculado. Con la sanción del Código Civil y Comercial, esa misma materia constitucional, enriquecida con los derechos de los tratados aludidos, se vuelca en su totalidad en el derecho privado argentino. ${ }^{30}$

El artículo 1711 prevé la llamada acción preventiva en estos términos: “Acción preventiva. La acción preventiva procede cuando una acción u omisión antijurídica hace previsible la producción de un daño, su continuación o agravamiento. No es exigible la concurrencia de ningún factor de atribución". ${ }^{31}$

La acción preventiva (que también puede ser colectiva) tiene por destinatario a quien está en condiciones de evitar la producción, repetición, persistencia o agravamiento de un daño posible, según el orden normal y corriente de las cosas. Esta acción debe prosperar en medida que el accionante posea un interés razonable. Excepcionalmente, se puede hacer valer contra quien, aunque no ha generado la amenaza de daño, se encuentra emplazado de modo tal que puede contribuir a evitar el daño o a morigerarlo. Reclama, eso sí, la existencia de una conducta antijurídica unida causalmente al daño posible. ${ }^{32}$

\footnotetext{
${ }^{29}$ Corte Suprema de Justicia de la Nación Argentina, "Bernabé Correa", fallos 138-157, 1926. La Corte Federal ha sostenido que "si bien las provincias tienen facultad constitucional de darse sus propias instituciones locales y, por ende, para legislar sobre procedimientos, ello es sin perjuicio de las disposiciones reglamentarias que dicte el Congreso, cuando considere del caso prescribir formalidades especiales para el ejercicio de determinados derechos establecidos en los códigos fundamentales que le incumbe dictar".

${ }^{30}$ Camps, Carlos Enrloue, "La pretensión preventiva de daños", Revista de Responsabilidad Civil y de Seguros, 2015-11, p. 12.

$254{ }^{31}$ En los Fundamentos del Anteproyecto del Código Civil y Comercial, se expresa que "la omisión del deber de prevención da lugar a la acción judicial preventiva, cuyos presupuestos son: a) autoria, que en este caso puede consistir en un hecho o una omisión de quien tiene a su cargo un deber de prevención del daño conforme con el artículo anterior; b) antijuridicidad, porque constituye una violación del mentado deber de prevención; c) causalidad, porque la amenaza de daño debe ser previsible de acuerdo con el régimen causal que se define en artículos siguientes; d) no es exigible la concurrencia de ningún factor de atribución, que es lo que, además de la función, diferencia a esta acción de la obligación de resarcir". El artículo 1032 del Código, luego de tratar la suspensión del cumplimiento del contrato, regula la llamada tutela preventiva: "Una parte puede suspender su propio cumplimiento si sus derechos sufriesen una grave amenaza de daño porque la otra parte ha sufrido un menoscabo significativo en su aptitud para cumplir, o en su solvencia. La suspensión queda sin efecto cuando la otra parte cumple o da seguridades suficientes de que el cumplimiento será realizado."

32 Peyrano, Jorge W., Más sobre la acción preventiva, La Ley, 2016-A, p. 1221.
} 
Aparte de la autoría, la norma requiere la antijuridicidad de la acción o la omisión que ha generado el peligro de daño. Este recaudo viene a funcionar como una garantía, pues se dirigirá una acción preventiva limitativa de la libertad del sujeto siempre que la conducta resulte antijurídica, en cuanto a la producción de un eventual perjuicio. ${ }^{33}$

Quizás la antijuridicidad deba ser determinada, partiendo de la consideración de que hay un deber genérico de no dañar y un deber de prevenir los daños. De tal modo, a la hora de precisar si una acción o una omisión reviste carácter antijurídico a los fines de la prevención, el operador del derecho deberá situarse en el caso concreto, centrando la atención en si existe o no un deber de prevención.

Cossari sostiene que adquiere especial relevancia el principio general de no dañar a otro, dado que todo hecho dañoso no justificado será antijurídico si viola el deber de prevención, sin necesidad de una prohibición legal expresa en cada caso. Este requisito se vuelve indispensable puesto que la ilegitimidad en la causación del daño es lo que fundamenta la restricción de la libertad del demandado. El hecho generador, en principio, debe ser ilícito, pero no se excluye el caso del acto ilícito potencialmente dañoso, aunque estos casos deberían apreciarse de manera más restrictiva; por otra parte, no rige la presunción de admisibilidad. Si del hecho del demandado se torna previsible una violación al deber de prevención, mediante un perjuicio no justificado por el derecho, se debe proceder a la acción preventiva. La antijuridicidad implica una conducta que viola el deber genérico de prevención y hace previsible el acaecimiento de un daño sin que esa conducta se encuentre amparada por una causal de justificación. ${ }^{34}$

Para Vázquez Ferreyra, lo que debe ser antijurídico es la conducta considerada en sí misma, es decir, violatoria del ordenamiento en general, incluidos los pactos contractuales, siempre que no se haya efectivizado el daño. Ante la amenaza de daño, la acción preventiva funcionaría solo contra conductas antijurídicas. La amenaza de daño no sería por sí misma una conducta antijurídica.

Si ya hubiese habido daño, la antijuridicidad sería palpable, por lo cual de por sí sería contraria a derecho. La simple amenaza de daño o la mera posibilidad de su ocurrencia no implica la violación del deber general de no dañar.

\footnotetext{
${ }^{33}$ Ordooul Castilla, Gustavo, "Prevención del daño y su tutela inhibitoria", Revista de Responsabilidad Civil y Seguros, 2010-4, p. 3. Explica Ordoqui Castilla que esta antijuridicidad está en la injusticia de la amenaza de daño, lo cual se debe valorar sustancialmente y no de manera meramente formal. Se asume aqui el concepto de antijuridicidad o ilicitud no solo formal (trasgresión de la norma); se sigue un criterio material en medida que el derecho es más que la ley, pues abarca la posible trasgresión de principios generales, la moral, las buenas costumbres.

${ }^{34}$ Cossari, MaXImiliano, Prevención y punición en la responsabilidad civil, Buenos Aires, El Derecho, 2017, pp. 78-79.
} 
Por dicha razón, propicia una antijuridicidad en sentido formal en materia de acción preventiva, incluido en el concepto las conductas abusivas. ${ }^{35}$

López Herrera afirma que una omisión solo puede ser antijurídica si existe un deber legal de actuar para prevenir el daño. Esa antijuridicidad no tiene que ser formal, sino comprensiva del ordenamiento jurídico en su totalidad. Es decir, allí donde exista un deber de actuación, impuesto por ley, reglamento, tratado internacional o por una tendencia jurisprudencial, se podrá plantear la acción preventiva. ${ }^{36}$

Además, se exige que esa actividad antijurídica cree la posibilidad previsiblemente evaluada de que se cause o de que se continúe causando un perjuicio. ${ }^{37}$ Se debe establecer una relación de causalidad entre la acción u omisión antijurídica y el daño que se pretende evitar, sea en su acaecimiento o en su agravamiento. ${ }^{38}$

En cuanto a la previsibilidad del daño que menciona el artículo $1711 \mathrm{del}$ Código Civil y Comercial de la Nación, se entiende que, por las máximas de la experiencia y proyecciones estimativas respaldadas en lo que normalmente ocurre, se puede llegar a determinar en ciertos casos un peligro de daño cierto. La factibilidad o probabilidad cierta debe ser cabalmente fundada. El estudio de probabilidad adelanta lo que puede ocurrir, anticipando, dentro de la lógica y lo razonable, un resultado (artículo 1726). ${ }^{39}$

El artículo no exige, en cambio, la concurrencia de un factor de atribución, subjetivo ni objetivo, para generar la responsabilidad preventiva. En este punto, la conclusión de las XXIII Jornadas Nacionales de Derecho Civil celebradas en Tucumán en setiembre de 2011, fue que "En la acción preventiva no es aplicable la noción de factor de atribución”. En disidencia, se propuso: "La imposición de un deber de prevención a un sujeto de derecho privado debe reposar en una razón o fundamento axiológico que justifique, adecuadamente, que la prevención de riesgo de daño sea asumida por un particular".

${ }^{35}$ VÁzouez Ferreyra, Roberto A., "La función preventiva de la responsabilidad civil. Antijuridicidad formal o material", Revista del Código Civil y Comercial, núm. 4.

${ }^{36}$ López Herrera, Edgardo, "Comentario art. 1711", en Julio César Rivera y Graciela Medina (dirs.), Código Civil y Comercial de la Nación comentado, tomo 4, Buenos Aires, La Ley, 2015.

${ }^{37}$ Zavala De González, Matilde, "La tutela inhibitoria contra daños", Revista de Responsabilidad Civil y Seguros, 1999, p. 2.

${ }^{38}$ Ordooui Castilla, Gustavo, "Prevención del daño y su tutela inhibitoria", Revista de Responsabilidad Civil y Seguros, 2010-4, p. 3 y ss.

${ }^{39}$ Bestani, AdRIAnA, "Acción preventiva y omisión precautoria en el nuevo Código Civil y Comercial", Revista del Código Civil y Comercial, núm. 11, p. 111. 
Para Camps, se debió haber indicado que no es necesaria la demostración de un factor subjetivo de atribución (dolo o culpa). Basta, entonces, con evidenciar el supuesto de hecho que aprehende la norma (una acción u omisión antijurídica que hace previsible la producción de un daño, su continuación o agravamiento) para que pueda plantearse en justicia el pedido de adopción de medidas preventivas o bien, que se limiten las consecuencias del daño en curso. Por otro lado, la ley busca que la prevención sea rápida y eficaz; exigir la demostración de la culpa de alguien llevaría, en muchos casos, a la esterilización de las buenas intenciones del remedio propuesto. Si el peticionante es arriesgado, responderá, como en todos los casos, por el abuso de la medida cautelar solicitada. Por otro lado, el juez aplicará el código de rito y exigirá la correspondiente contracautela, con lo cual se despeja bastante el riesgo de acciones preventivas aventuradas. ${ }^{40}$

Picasso y Sáenz postulan que la norma prevé una particularidad de la acción preventiva que la distingue sustancialmente del proceso resarcitorio clásico. En efecto, para la procedencia de la demanda tendiente a evitar que el daño se produzca, no será preciso que se encuentre configurado un factor de atribución. En este tipo de acciones, es muy común que la pretensión se dirija a detener una conducta que aún no ha comenzado a realizarse, por lo cual difícilmente puede evaluarse si el factor de atribución se encuentra presente. Esta previsión cobra especial relevancia cuando el accionar del agente, para que surja el deber de resarcir el daño ya ocasionado, requiere la configuración de un factor de atribución subjetivo (dolo o culpa). ${ }^{41}$

Para que opere una medida inhibitoria o de prevención ante un daño inminente, es necesario que exista la posibilidad de detener la acción que la motivó. Así, cumpliendo la orden que imparta el juez, es posible evitar o hacer cesar el daño. Si el daño ya se causó, la medida provisional o inhibitoria no tiene sentido, a menos que se pretenda evitar su agravamiento. ${ }^{42}$

\footnotetext{
${ }^{40}$ Camps, Carlos Enrique, "La pretensión preventiva de daños", Revista de Responsabilidad Civil y de Seguros, núm. 11, p. 12. Tolosa, Pamela, "Función de prevención y la acción preventiva de daños en el nuevo proyecto de Código Civil y Comercial", Revista de Responsabilidad Civil y Seguros, 2012-12, p. 14. Para Tolosa, la exclusión de la necesidad de un factor de atribución entre los requisitos de estas acciones implica que se intenta facilitar y agilizar el reclamo, limitando los posibles obstáculos que pudieran dilatar o dificultar una medida de prevención en el marco de esta acción; la interpretación de las normas procesales que corresponda aplicar al encauzar esta acción deberá considerar este criterio".

${ }^{41}$ Picasso, Sebastián y SaÉnz, Luis R., "Comentario al artículo 1709", en Marisa Herrera, Gustavo Caramelo y Sebastián Picasso, (dirs.), Código Civil y Comercial de la Nación, tomo 4, Buenos Aires, Infojus, 2015, p. 421. Cossari, Maximiliano, Prevención y punición en la responsabilidad civil, Buenos Aires, El Derecho, 2017, p. 85.

${ }^{42}$ Ordooui Castilla, Gustavo, "Prevención del daño y su tutela inhibitoria", Revista de Responsabilidad Civil y Seguros, 2010-4, pp. 3 y ss.
} 


\section{La legitimación sustancial activa y pasiva en la acción preventiva}

Respecto de la legitimación activa, el artículo 1712 establece que "están legitimados para reclamar quienes acreditan un interés razonable en la prevención del daño".

Desde la doctrina, ya se anticipaba que para los fines de la procedencia de la tutela inhibitoria contra daños, debía demostrarse que el perjuicio afecta un interés y que este puede surgir de la existencia de un derecho subjetivo, interés legítimo o interés simple, en el caso de la titularidad individual. Así, también es procedente cuando se invoque una titularidad difusa o colectiva en los términos del artículo 43 de la Constitución Nacional. ${ }^{43}$

Dentro de los derechos de incidencia colectiva, el artículo 43 de la Constitución Nacional menciona expresamente los de no sufrir discriminaciones y la protección del ambiente, la competencia, el usuario y el consumidor. ${ }^{44}$

A los efectos de evaluar la legitimación, el Código propone una fórmula flexible: que el peticionante tenga un "interés razonable". En este sentido, la conclusión de las XXIII Jornadas Nacionales de Derecho Civil, precisamente, fue: "Están legitimados activamente para obrar todos aquellos que acrediten un interés mínimo pero razonable, individual o colectivo".

$\mathrm{Al}$ respecto, cabe apuntar que irrazonable es aquello que carece de razón; no razonable, para definir a la razón, justicia, rectitud en las operaciones o derecho para ejecutarlas. Mientras, razonable: "Es lo arreglado, justo, conforme a razón. Lo razonable es lo opuesto a lo arbitrario y significa conforme a la razón, justo, moderado, prudente", todo lo cual puede ser resumido, con arreglo a lo que dice el sentido común. ${ }^{45}$

Para Baracat, el texto legal no habla de interés directo o indirecto. Simplemente introduce el concepto de "interés razonable" y tendrá que ser el magistrado, a través de la sana crítica, quien determine en cada caso concreto si el peticionante ostenta el citado interés. En su entendimiento, la noción alude a una relación de riesgo o amenaza mensurable con base en el sujeto peticionante, 258 la situación de hecho expuesta como causa petendi y el sujeto activo de la antijuridicidad o destinatario de la medida preventiva. No es posible requerir

\footnotetext{
${ }^{43}$ LorenzettI, Ricardo Luis, "La tutela civil inhibitoria", La Ley, 1995-C, p. 1223.

${ }^{44}$ Zavala De González, Matilde, "La tutela inhibitoria contra daños", Revista de Responsabilidad Civil y Seguros, 1999, p. 4; Nicolau, Noemi Lidia, "La tutela inhibitoria y el nuevo artículo 43 de la Constitución Nacional", La Ley, 1996- A, p. 1250.

${ }^{45}$ Vázouez Ferreyra, Roberto A., "La razonabilidad en el Derecho de las Obligaciones", en Oscar Ameal (dir.), Obligaciones y contratos en los albores del Siglo Xxı. Homenaje al profesor doctor Roberto M. López Cabana, Buenos Aires, Depalma, 2001, pp. 429 y ss. ARAZI, RoLAnd, "La legitimación en la acción preventiva", Revista de Derecho Procesal, 2016-1, pp. 301 y ss.
} 
una tutela inhibitoria que, aun cuando tienda a evitar un ilícito, acabe causando un daño excesivo al demandado. ${ }^{46}$

López Herrera enuncia los siguientes parámetros para determinar si existe o no interés razonable en la prevención:

- Ser la posible víctima del daño: aquel que sufriría un daño personal tanto como damnificado directo como indirecto. El damnificado directo que esté sufriendo o pueda previsiblemente sufrir un daño tendrá habilitada la vía preventiva y se presumirá la existencia de un interés razonable en la prevención. Es más compleja la situación que plantea el damnificado indirecto, que debería demostrar su interés aún de manera sumaria, como sería el caso del padre que debe desembolsar los gastos por la posible enfermedad de su hijo, quien es damnificado indirecto que sufre un daño emergente personal.

- Tener legitimación para la defensa de intereses de incidencia colectiva, como es el caso de asociaciones de defensa del medio ambiente o los consumidores. En los procesos colectivos, la pretensión preventiva puede ser ejercida no solo por el titular del derecho, sino, en general, por el afectado, por el defensor del pueblo, por ciertas asociaciones (artículo 43, segundo párrafo, de la Constitución Nacional). Asimismo, por toda persona, en el especial caso de la pretensión de cese de daño ambiental colectivo de acuerdo con el artículo 30 de la Ley 25.675. Puede incluirse también a las organizaciones no gubernamentales reconocidas, los defensores de las comunidades indígenas y las entidades civiles que protegen derechos colectivos o intereses difusos.

- Estar obligado a actuar. Se refiere a personas tanto públicas como privadas que se encuentran obligadas a prevenir el daño. Por ejemplo, en caso de consorcio de propiedad horizontal, cuando se necesitara ingresar al departamento de un consorcista que está dañando a los demás miembros, pero que se niega a dejar realizar reparaciones urgentes. ${ }^{47}$

Más allá de la amplia legitimación activa regulada en la norma, es un requisito primordial - no ya de la acción preventiva, sino del proceso judicial en

\footnotetext{
${ }^{46}$ Baracat, Edgar J., "Herramientas procesales para la prevención del daño en el nuevo Código Civil y Comercial", La Ley, 13 de julio, 2015, p. 1.

${ }^{47}$ López Herrera, Edgardo, "Comentario art. 1711", en Julio César Rivera y Graciela Medina (dirs.), Código Civil y Comercial de la Nación comentado, tomo 4, Buenos Aires, La Ley, 2015, p. 1002. Benedetto DI, Tomás M., "La legitimación para interponer la acción preventiva", en Jorge W. Peyrano (dir.), La acción preventiva en el Código Civil y Comercial de la Nación, Santa Fe, Rubinzal Culzoni, 2016, p. 55.
} 
general- que quien promueva la acción plantee un caso concreto. Es decir, el interesado deberá demostrar que persigue la determinación del derecho debatido, y que tiene un interés jurídico suficiente en la resolución de la controversia. Por ende, en la acción preventiva, debe demostrarse que quien acciona es titular de un derecho subjetivo o un interés legítimo, o que cuenta con legitimación suficiente para tutelar un interés difuso determinado. Asimismo, que existe una amenaza cierta de que se produzca un daño ilegítimo. ${ }^{48}$

Como un caso puntual de legitimación, se debe señalar la posibilidad que tienen los consumidores de solicitar medidas preventivas en materia de publicidad ilícita. En este aspecto, el artículo 1102 dispone: "Acciones. Los consumidores afectados o quienes resulten legalmente legitimados pueden solicitar al juez: la cesación de la publicidad ilícita, la publicación, a cargo del demandado, de anuncios rectificatorios y, en su caso, de la sentencia condenatoria”.

En cuanto a la legitimación sustancial pasiva, se advierte que la acción deberá dirigirse contra todos aquellos que, de ocurrir el daño, podrían ser encontrados responsables civilmente, de manera directa, indirecta o por la intervención de cosas o la realización de actividades riesgosas o peligrosas. Resulta lógico que se le pueda exigir la prevención de un daño a quien, una vez concretado el perjuicio, debería hacerse cargo de la indemnización correspondiente.

Asimismo, podrían ser demandados aquellos que tengan a su cargo un deber de prevención específico impuesto por el ordenamiento jurídico y aquellos que, sin ser productores del daño, permiten o coadyuvan a su producción, mediante colaboración, permisividad, negligencia o incumplimiento de su obligación de prevenir los mismos.

El Estado o entes públicos tendrán legitimación pasiva cuando ocurran actos u omisiones ilícitas de terceros y se atribuya a ellos el cumplimiento de sus funciones de contralor o supervisar un servicio público, en medida que exista una real posibilidad de evitar o controlar el perjuicio. ${ }^{49}$

\section{La sentencia preventiva de daños}

El artículo 1713 regula la sentencia en la acción preventiva en estos términos: "La sentencia que admite la acción preventiva debe disponer, a pedido de parte o de oficio, en forma definitiva o provisoria, obligaciones de dar, hacer o no hacer, según corresponda; debe ponderar los criterios de menor restricción

\footnotetext{
${ }^{48}$ Picasso, Sebastián y Saénz, Luis R., "Comentario al artículo 1709", en Marisa Herrera, Gustavo Caramelo y Sebastián Picasso, (dirs.), Código Civil y Comercial de la Nación, tomo 4, Buenos Aires, Infojus, 2015, pp. 421-422.

${ }^{49}$ Cossari, Maximillano, Prevención y punición en la responsabilidad civil, Buenos Aires, El Derecho, 2017, pp. 90-92.
} 
posible y de medio más idóneo para asegurar la eficacia en la obtención de la finalidad". ${ }^{50}$

Es importante que, desde el derecho sustancial, el Código admita la facultad de los jueces de disponer oficiosamente medidas de prevención de daños, de modo que ya no serán viables los cuestionamientos a sentencias de este tenor por una eventual violación al principio de congruencia procesal.

La redacción de la norma deja abierta la discusión acerca de si comprende o no la llamada jurisdicción preventiva que oficiosamente podría activar un magistrado, cuando toma conocimiento de la posibilidad de que se produzca un daño al actor o a un tercero ajeno.

Se interpreta que la norma se refiere a las facultades del juez que intervienen en la acción preventiva, para evitar que se concrete el perjuicio en cabeza de la víctima. Con tal fin, la disposición confiere un amplio poder a los magistrados para adoptar las medidas que resulten más apropiadas, y se aparta del principio dispositivo que, en general, rige en el derecho privado. ${ }^{51}$

La resolución judicial que admita una medida de prevención puede tener lugar en forma definitiva o provisoria. Ello quiere decir que es posible la existencia de una tutela inhibitoria definitiva, que tramite por vía de proceso ordinario, y otra cautelar, que tiene una función anticipatoria o precautoria de la primera, según los casos.

La tutela inhibitoria admite una acción definitiva y otra cautelar que se diferencian, precisamente, por su instrumentación procesal: las separa el procedimiento aplicable. La vía cautelar no admite un amplio debate de cuestiones (conocimiento limitado) y su característica saliente está dada por el recaudo de la urgencia, la brevedad temporal. En cambio, la tutela final está más vinculada con la amenaza de daño que con el peligro en la demora. De tal manera, se puede discernir entre un perjuicio derivado del transcurso del tiempo del proceso, que autoriza la cautelar, y otro derivado del hecho ilícito. En este último supuesto, el tiempo del proceso no es una variable con aptitud para distorsionar el resultado final. Dentro del género de la tutela inhibitoria, tanto la defınitiva como la cautelar están unidas por la finalidad preventiva. Para tales

\footnotetext{
${ }^{50}$ Conforme a los fundamentos del Anteproyecto, "se delimitan los siguientes criterios para la sentencia de finalidad preventiva: a) se distingue entre la tutela definitiva que surge de un proceso autónomo cuya finalidad es únicamente la prevención, de aquellos en que es provisoria; b) en ambos supuestos, la sentencia puede establecer obligaciones de dar, hacer o no hacer, según los casos; c) el contenido y extensión de estas obligaciones debe estar guiado por: la necesidad de evitar el daño con la menor restricción de derechos posible; la utilización del medio más idóneo; la búsqueda de la eficacia en la obtención de la finalidad. Estos parámetros permiten una valoración más exacta y un control judicial sobre las medidas que se adopten; $d$ ) el juez puede disponer esas medidas a pedido de parte o de oficio".

${ }^{51}$ Picasso, Sebastián y SaÉnz, Luis R., "Comentario al artículo 1709", en Marisa Herrera, Gustavo Caramelo y Sebastián Picasso, (dirs.), Código Civil y Comercial de la Nación, tomo 4, Buenos Aires, Infojus, 2015, p. 421.
} 
fines, ambas admiten una concretización mediante mandatos de innovación y de no innovación. ${ }^{52}$

A pesar de estas precisiones, el Código no menciona vías procesales en particular. Por tanto, la consagración amplia de tutela definitiva o provisoria habilita a encuadrar las diversas situaciones, sea en las medidas cautelares clásicas, en las medidas autosatisfactivas o en las medidas anticipatorias o de tutela anticipada. ${ }^{53}$

Para Calvo Costa, si el daño aún no se produjo, pero existe probabilidad razonable de su ocurrencia, el objeto de la pretensión preventiva será lograr impedir que el riesgo de daño se concrete. Frente a ello, podrá disponer el juez interviniente -en forma provisoria o definitiva- obligaciones de dar, hacer o no hacer. En tal sentido, una sentencia de una pretensión preventiva puede ordenar la entrega de algo (v.gr. una prótesis en un caso médico de urgencia), la realización de una actividad (v.gr. que se retire del mercado una partida de medicamentos adulterados o defectuosos), o el cese de una conducta (v.gr. que se suspenda la construcción de una obra que se erige en una amenaza de daño por el riesgo de derrumbe).

A pesar de lo anterior, para algunos autores tales medidas pueden ser adoptadas de oficio por los magistrados, pero, para que sean dispuestas en forma definitiva, deberá realizarse a pedido de parte y respetando la biteralización del proceso. En cambio, si el daño ya ha comenzado a producirse, la acción preventiva perseguirá que las consecuencias lesivas se detengan o no se agraven. En tal caso, por la premura de la adopción de medidas, resultarán de gran utilidad las medidas cautelares de cese, minimización o no agravamiento del daño. ${ }^{54}$

$\mathrm{Al}$ respecto, cabe citar las conclusiones de las III Jornadas Marplatenses de Responsabilidad Civil y Seguros, realizadas en Mar del Plata, del 25 al 27 de octubre de 2012.

Las funciones de la responsabilidad. Constituye una acción de prevención específica sustancial que persigue evitar la producción, continuación o agravamiento de un daño, en forma provisoria o definitiva, principal o accesoria. Será operativa a través de las herramientas

\footnotetext{
52 Lorenzetti, Ricardo Luis, "La tutela civil inhibitoria", La Ley, 1995-C, p. 1223.

${ }^{53}$ En la XIII Conferencia Nacional de Abogados celebrada en abril de 2000 en San Salvador de Jujuy se sostuvo: "La tutela inhibitoria es un eficaz medio de evitación, tanto desde el derecho sustancial como desde el procedimental. Tiene sustento constitucional (artículo 43, Constitución Nacional), puede aplicarse tanto a las partes en un juicio como a un tercero, consistiendo en una orden de hacer o de abstenerse. Más allá de su reconocimiento de lege ferenda, son numerosos los supuestos existentes de lege lata".

${ }^{54}$ Calvo Costa, Carlos A., "La prevención: la otra cara de la responsabilidad civil (¿0 del derecho de daños?)", Revista de Responsabilidad Civil y Seguros, núm. 3, p. 20.
} 
procesales disponibles que resulten más adecuadas. Entre ellas: acción de amparo, medidas cautelares en su rol preventivo y las llamadas medidas autosatisfactivas y de tutela anticipatoria. Ello sin perjuicio de la legislación procesal provincial que se dicte al efecto.

La cuestión de la tutela inhibitoria se vincula básicamente con la salvaguarda y protección de los derechos, e involucra la construcción de un procedimiento autónomo capaz de garantizar la prestación de una tutela susceptible de inhibir la práctica, la repetición o la continuación del evento dañoso; en este sentido, la tutela sustancial inhibitoria tiene como objeto directo la prevención del daño mediante una orden para impedir que se cause, en caso de amenaza de lesión, o bien, para que cese su producción, si la actividad no se ha iniciado y es previsible su continuación o reiteración. ${ }^{55}$

El contenido de la resolución preventiva puede ser una obligación de dar, de hacer o de no hacer, según las circunstancias de cada caso. El principio general de prevención es inherente a cualquier ordenamiento jurídico preocupado por garantizar efectivamente el pleno ejercicio de los derechos. Por tanto, se vincula de manera directa con el acceso a la justicia, consagrado en el derecho argentino en el artículo 18 de la Constitución Nacional. ${ }^{56}$

El artículo se encarga de especificar que el juez debe ponderar los criterios de "menor restricción posible" y de "medio más idóneo" para asegurar la eficacia en la obtención de la finalidad. Nuevamente, en este punto de la regulación del Código Civil y Comercial, aparece la necesidad de prudencia en la medida preventiva que se adopte. Ello obliga al juzgador a efectuar un juicio de ponderación o balance de los derechos o intereses en pugna, para la consecución del objetivo propuesto desde los límites que deben evaluarse. ${ }^{57}$

Para Galdós, la medida y razonabilidad de la extensión del mandato debe resultar de un juicio de ponderación. En tal sentido, se ha de minimizar la restricción del derecho limitado y considerar su idoneidad en busca de la eficacia del resultado. Se trata del juicio de comparación entre la entidad y atendibilidad

\footnotetext{
${ }^{55}$ Zavala De González, Matilde, "La tutela inhibitoria contra daños", Revista de Responsabilidad Civil y Seguros, 1999, p. 2. Lorenzetti, por su parte, sostiene que "la tutela resarcitoria consiste en la indemnización del perjuicio sufrido ya sea in natura o mediante una compensación monetaria. (Artículo 1083 Código Civil). En este caso, el concepto de acción procesal se identifica con el momento patológico de la violación del derecho sustantivo. De tal modo está condicionada a la deducción en juicio de una pretensión basada en la prueba de la fattispecie descripta en la norma de fondo, esto es, de la prueba del perjuicio. La tutela inhibitoria, en cambio, tiene finalidad preventiva. El elemento activante es la posibilidad de un ilícito futuro, es la amenaza de violación". LoRenzetti, Ricardo LuIS, "La tutela civil inhibitoria", La Ley, 1995-C, pp. 1217 y ss.

${ }^{56}$ Marinoni, Luiz Guilherme, "Tutela inhibitoria: la tutela de prevención del ilícito", ED 186, p. 1127.

${ }^{57}$ Baracat, Edgar J., "Herramientas procesales para la prevención del daño en el nuevo Código Civil y Comercial", La Ley, 13 de julio, 2015, p. 1.
} 
de los derechos en pugna, debiendo prevalecer los extrapatrimoniales por sobre los patrimoniales, los derechos de incidencia colectiva sobre los derechos individuales, según la naturaleza de los intereses en conflicto, y predominar la tutela de la persona por sobre el patrimonio. ${ }^{58}$

Siguiendo a Tolosa, decimos que, para evaluar la procedencia de la medida preventiva según los criterios de "menor restricción posible” y "medio más idóneo", el juez deberá considerar las circunstancias empíricas relevantes en cada caso. Dicha evaluación debería implicar dos instancias. Por un lado, analizar en qué tipo de casos será preferible optar por la acción preventiva. Es decir, si no estamos dispuestos a eliminar los riesgos completamente y aceptamos que cierto nivel de calidad de vida en una sociedad implica tolerar algunos de estos riesgos, la acción preventiva no procederá para evitar cualquier daño. Por otro lado, el juez deberá evaluar cuál es la mejor alternativa disponible, y la menos costosa, para exigir que se prevenga el daño o su agravación; en el caso concreto, cuál será el contenido de la obligación de hacer, dar o no hacer que imponga. ${ }^{59}$

\section{Reflexiones de cierre}

El Código Civil y Comercial proporciona herramientas para el desarrollo de una función preventiva de la responsabilidad civil, que, hasta el momento, no contaba con una regulación propia, sistemática e integral, más allá de la recepción de concretas aplicaciones en normas especiales.

Sin duda, la prevención de los daños configura la función primordial que la responsabilidad civil ha tomado dentro de su ámbito por decisión del legislador, conviviendo armónicamente con la tradicional función resarcitoria.

Existe un derecho a no ser dañado, máxime desde la perspectiva propuesta por el Código en que se coloca a la persona como epicentro del sistema normativo. Sin embargo, las normas destinadas a la prevención de los daños han generado y seguirán generando muchas interrogantes e inquietudes. La responsabilidad civil ha transitado un largo camino en la búsqueda de la protección efectiva de las víctimas de daños injustos para obtener no solo su reparación, sino lo que es más valioso: su prevención.

\footnotetext{
${ }^{58}$ Galdós, Jorge Mario, "Las funciones de la responsabilidad civil. La supresión de la sanción pecuniaria disuasiva en el código Civil y Comercial de la Nación", La Ley, Suplemento Especial Nuevo Código Civil y Comercial 2014-11, p. 137.

59 Tolosa, Pamela, "Función de prevención y la acción preventiva de daños en el nuevo proyecto de Código Civil y Comercial", Revista de Responsabilidad Civil y Seguros, núm. 12, p. 14.
} 


\section{Bibliografía}

Acciarri, Hugo A., "Funciones del derecho de daños y de prevención”, La Ley, 2013-A. Acciarri, Hugo A., "El Genovese effect, los jueces y el Proyecto de Reforma al Código

Civil argentino de 2012”, Revista de Responsabilidad Civil y de Seguros, 2014-7.

Alterini, Atilio Aníbal, "Soluciones del Proyecto de Código en materia de responsabilidad civil”, La Ley, 30 de julio, 2012.

ARAZI, Roland, "La legitimación en la acción preventiva”, Revista de Derecho Procesal, 2016-1.

BARACAT, Edgar J., "Herramientas procesales para la prevención del daño en el nuevo Código Civil y Comercial”, La Ley, 13 de julio, 2015.

Benedetto DI, TomÁs M., "La legitimación para interponer la acción preventiva", en Jorge W. Peyrano (dir.), La acción preventiva en el Código Civil y Comercial de la Nación, Santa Fe, Rubinzal Culzoni, 2016.

Bestani, Adriana, "Acción preventiva y omisión precautoria en el nuevo Código Civil y Comercial”, Revista del Código Civil y Comercial, núm. 11.

Calvo Costa, Carlos A., "La prevención: la otra cara de la responsabilidad civil (¿0 del derecho de daños?)", Revista de Responsabilidad Civil y Seguros, núm. 3.

CAmps, CARlos EnRIQue, “La pretensión preventiva de daños”, Revista de Responsabilidad Civil y de Seguros, núm. 11.

Corte Suprema de Justicia de la Nación Argentina, “Bernabé Correa”, fallos 138-157, 1926. Cossari, Maximiliano, Prevención y punición en la responsabilidad civil, Buenos Aires, El Derecho, 2017.

Fernández Madero, Jaime, Derecho de daños. Nuevos aspectos doctrinarios y jurisprudenciales, Buenos Aires, La Ley, 2002.

Galdós, Jorge Mario, "Las funciones de la responsabilidad civil. La supresión de la sanción pecuniaria disuasiva en el código Civil y Comercial de la Nación”, La Ley, Suplemento Especial Nuevo Código Civil y Comercial, núm. 11.

Galdós, Jorge Mario, “La responsabilidad civil (parte general) en el Anteproyecto”, La Ley, 11 de junio, 2012.

Kemelmajer de Carlucci, Aida, "La Ley sobre Riesgos del Trabajo 24.557 y los principios generales del Derecho de Daños desde la óptica del Derecho Constitucional”, Revista de Derecho Privado y Comunitario, tomo 15.

López Herrera, Edgardo, "Comentario art. 1711", en Julio César Rivera y Graciela Medina (dirs.), Código Civil y Comercial de la Nación comentado, tomo 4, Buenos Aires, La Ley, 2015.

López Herrera, Edgardo, "La función preventiva de la responsabilidad civil y su relación con las otras funciones", Revista de Derecho de Daños, núm. 2.

LorenzetTI, Ricardo Luis, "La tutela civil inhibitoria”, La Ley, 1995-C.

LORENZETTI, RicARDo, "Aspectos valorativos y principios preliminares del Anteproyecto de Código Civil y Comercial de la Nación”, La Ley, 23 de abril, 2012. 
Lorenzetti, Ricardo Luis, Normas fundamentales del derecho privado, Santa Fe, Rubinzal-Culzoni, 1995.

MARINONI, Luiz GuILHERme, “Tutela inhibitoria: la tutela de prevención del ilícito”, ED 186.

Messina de Estrella Gutiérrez, Graciela N., La responsabilidad civil en la era tecnológica. Tendencias y prospectiva, Buenos Aires, Abeledo Perrot, 1997.

Morales Hervías, Rómulo, "Responsabilidad civil y análisis económico del derecho”, Revista de Responsabilidad Civil y Seguros, vol. 3, núm. 4.

Nicolau Noemí Lidia, "La tutela inhibitoria y el nuevo artículo 43 de la Constitución

Nacional”, La Ley, 1996-A.

Ordoqui Castilla, Gustavo, "Prevención del daño y su tutela inhibitoria", Revista de

Responsabilidad Civil y Seguros, núm. 4.

Padilla, RenÉ, Sistema de la responsabilidad civil, Buenos Aires, Abeledo Perrot, 1997.

Perdía, Natali, "La responsabilidad preventiva en el nuevo Código Civil y Comercial”,

Revista de Responsabilidad Civil y Seguros, núm. 9, pp. 26-32.

Peyrano, Jorge W., Más sobre la acción preventiva, La Ley, 2016-A.

Picasso, Sebastián y SaÉnz, Luis R., “Comentario al artículo 1709”, en Marisa Herrera,

Gustavo Caramelo y Sebastián Picasso (dirs.), Código Civil y Comercial de la

Nación, tomo 4, Buenos Aires, Infojus, 2015.

Pizarro, Ramón y Vallespinos, Carlos, Instituciones de derecho privado. Obligaciones, tomo 3, Buenos Aires, Hammurabi, 2000.

“Prevención”, Diccionario Enciclopédico Marred, España, Trébol, 1998.

“Prevenir”, Diccionario Enciclopédico Marred, España, Trébol, 1998.

Prevot, Juan Manuel, "La prevención del daño en la codificación del siglo xix y en el Código Civil Argentino”, Revista de Derecho de Daños, 2008-2.

Sema, José Ignacio, "La función preventiva de la responsabilidad civil en el Código

Civil y Comercial. Fundamentos de su reconocimiento legal”, Pensamiento civil, p. 1. Disponible en: https://www.pensamientocivil.com.ar/doctrina/2173-funci on-preventiva-responsabilidad-civil-codigo-civil-y-comercial

Tolosa, Pamela, "Función de prevención y la acción preventiva de daños en el nuevo proyecto de Código Civil y Comercial”, Revista de Responsabilidad Civil y Seguros, 2012-12.

VÁzquez Ferreyra, Roberto A., "La función preventiva de la responsabilidad civil. Antijuridicidad formal o material”, Revista del Código Civil y Comercial, núm. 4. Venini, Juan Carlos, "El deber de la víctima de mitigar el daño", Revista de Derecho de Daños, 2008-2.

Vergara, LeAndro, "La prevención en el derecho de la responsabilidad civil”, Revista de Responsabilidad Civil y Seguros, vol. 5, núm. 6.

VÁzquez Ferreyra, Roberto A., "La razonabilidad en el Derecho de las Obligaciones", en Oscar Ameal (dir.), Obligaciones y contratos en los albores del Siglo XXI. 
Homenaje al profesor doctor Roberto M. López Cabana, Buenos Aires, Depalma, 2001.

Zavala de GonzÁlez, Matilde, "Función preventiva de daños”, La Ley, 3 de octubre, 2011.

Zavala de GonzÁlez, Matilde, Resarcimiento de daños, presupuestos y funciones del derecho de daños, tomo 4, Buenos Aires, Hammurabi, 1999.

Zavala De GonzÁlez, Matilde, “La tutela inhibitoria contra daños”, Revista de Responsabilidad Civil y Seguros, 1999. 